\title{
Optimization of Carbon Coatings on $\mathrm{LiFePO}_{4}$
}

\author{
Marca M. Doeff,* James D. Wilcox, ${ }^{*}$ Robert Kostecki ${ }^{\dagger}$, and Grace Lau* \\ *Materials Sciences Division and ${ }^{\dagger}$ Environmental Energy Technologies Division \\ Lawrence Berkeley National Laboratory \\ University of California \\ Berkeley, CA 94720 USA
}

\section{Acknowledgment}

This work was supported by the Assistant Secretary for Energy Efficiency and Renewable Energy, Office of FreedomCAR and Vehicle Technologies of the U.S. Department of Energy under contract no. DE-AC03-76SF00098. We would like to thank Dr. Gao Liu of Lawrence Berkeley National Laboratory for providing carbon-coated current collectors. 


\begin{abstract}
The electrochemical performance of $\mathrm{LiFePO}_{4}$ in lithium cells is strongly dependent on the structure (disordered/graphene or $\mathrm{D} / \mathrm{G}$ ratio) of the in situ carbon produced during synthesis from carbon-containing precursors. Addition of pyromellitic acid (PA) prior to final calcination results in lower $\mathrm{D} / \mathrm{G}$ ratios, yielding a higher-rate material. Further improvements in electrochemical performance are realized when graphitization catalysts such as ferrocene are also added during $\mathrm{LiFePO}_{4}$ preparation, although overall carbon content is still less than 2 wt. \%.
\end{abstract}

\title{
Keywords
}

Lithium iron phosphate, lithium batteries, carbon, conductive coatings

\section{Introduction}

$\mathrm{LiFePO}_{4}$ is of interest as a cathode material for Li-ion batteries intended for largescale applications such as hybrid electric vehicles (HEVs) because of its potential for low cost and improved safety. To fulfill this promise, however, the power capability of this material needs to be improved. A factor limiting the performance of $\mathrm{LiFePO}_{4}$ is its low electronic conductivity, calculated to be about $10^{-9} \mathrm{~S} / \mathrm{cm}$ at room temperature [1]. Although an attempt to improve the intrinsic conductivity by doping with multivalent cations has been reported recently [2], it is not clear that substitution on the Li sites actually occurs under the conditions described $[3,4]$. In contrast, it has been shown that carbon-coating the $\mathrm{LiFePO}_{4}$ particles [5] results in greatly improved room-temperature electrochemical performance. This may be accomplished by adding organic or polymeric precursors during synthesis [6], although the total amount of carbon should be kept low 
to avoid adversely affecting the tap density [7]. To maximize power capability without incurring an energy density penalty, it is therefore necessary to optimize the conductivity of the coating.

Higher electronic conductivity scales with lower D/G (disordered/graphene) and increased $\mathrm{sp}^{2} / \mathrm{sp}^{3}$ ratios in carbon [8]. We have previously noted a correlation between the structure of carbon in $\mathrm{LiFePO}_{4}$ samples and the utilization upon discharge in lithium cells at room temperature [9]. Significantly, some materials with low amounts of carbon and low $\mathrm{D} / \mathrm{G}$ ratios outperformed those with more carbon having a more disordered structure. While optimizing the carbon structure is key to obtaining good performance, it is difficult to produce highly graphitic coatings at the relatively low temperatures $\left(600-800^{\circ} \mathrm{C}\right)$ used for synthesis of $\mathrm{LiFePO}_{4}$ [8]. Herein we show how, with the proper choice of additives and graphitization catalysts [10], better coatings may be produced, which result in greatly enhanced electrochemical behavior.

\section{Experimental}

$\mathrm{LiFePO}_{4}$ was synthesized by a sol-gel procedure described in our previous publications $[9,11]$. Pyromellitic acid (PA) and ferrocene were dissolved in acetone or ethanol and added to the sample after initial firing at $500^{\circ} \mathrm{C}$ under flowing $\mathrm{N}_{2}$. This mixture was then planetary milled for 1 hour, dried, and subjected to a final firing at $600^{\circ} \mathrm{C}$ under flowing nitrogen for ten hours.

The phase purity of samples was verified by x-ray powder diffraction (XRD) using a Philips $\mathrm{X}$ 'Pert diffractometer with monochromatized $\mathrm{Cu}-\mathrm{K} \alpha$ radiation. The carbon and hydrogen contents of selected samples were measured by Luvak, Inc. (Boylston, MA).

An integrated Raman microscope system ' 'Labram' made by ISA Groupe Horiba 
was used to observe individual particles of $\mathrm{LiFePO}_{4}$. The excitation wavelength was supplied by an internal He-Ne $(632 \mathrm{~nm}) 10 \mathrm{~mW}$ laser. The power of the laser beam was adjusted to $0.1 \mathrm{~mW}$ with neutral filters of various optical densities. The size of the laser beam at the sample was $\sim 1.2 \mu \mathrm{m}$.

Laminated electrodes containing 80 wt $\%$ active material, 8 wt \% Kynar poly(vinylidene fluoride) (PVdF binder grade 2801-00, lot 97C8118, Elf Atochem North America, Inc., Technical Polymers Department), 6 wt \% SFG-6 synthetic flake graphite (Timcal Ltd., Graphites and Technologies), and 6 wt \% compressed acetylene black were prepared as previously described [9.] Electrodes were punched out to $1.8 \mathrm{~cm}^{2}$ size, with loadings of about $5-10 \mathrm{mg} / \mathrm{cm}^{2}$ active material. For some experiments, carbon-coated aluminum current collectors were used as backings for the positive electrodes. The thickness of the carbon coating was approximately $5 \mu \mathrm{m}$.

2032 size coin cells were assembled in a helium-filled glove box, using lithium metal as a counter electrode and $1 \mathrm{M}$ LiPF6 in 1:2 ethylene carbonate/dimethyl carbonate (EC/DMC) as the electrolytic solution (Merck). Cells were cycled galvanostatically between 2.0 and $3.9 \mathrm{~V}$ at various rates using a MacPile II (Bio-Logic, SA, Claix, France) potentiostat/galvanostat.

\section{Results and Discussion}

$\mathrm{LiFePO}_{4}$ may be prepared by a number of different routes, including hydrothermal synthesis [12, 13], carbothermal reduction [14], sol-gel $[9,15,16,17]$ or aqueous precipitation routes [18], microwave processing [19], and solid-state synthesis under an inert or reducing atmosphere [20, 21]. Samples made from precursors with organic moieties (oxalates, acetates, etc.) [9] or processed in plastic containers [3] typically contain small amounts of residual (in situ) carbon from pyrolysis of the organics or polymers. Even small amounts of in situ carbon may turn samples deep gray or black 
(Figure 1) so that color is not a reliable indicator of successful doping with aliovalent ions, unless contact with carbonaceous materials was strictly avoided during preparation.

The amount of residual carbon present in samples varies in complex ways with the furnace conditions; some is lost as $\mathrm{CO}$ or $\mathrm{CO}_{2}$ during carbothermal reduction, particularly if $\mathrm{Fe}(\mathrm{III})$ species are present. Near or above $800^{\circ} \mathrm{C}$, these processes may result in the formation of iron carbide, iron phosphocarbides and/or iron phosphides from reaction with $\mathrm{LiFePO}_{4}$ itself $[3,4]$. Nevertheless, the presence of carbon or carbonaceous materials during synthesis is beneficial as grain growth is inhibited and oxidation of iron by adventitious oxygen is slowed or prevented.

The structure of the in situ carbon influences the electrochemical behavior of $\mathrm{LiFePO}_{4}$ samples. Electrode utilization rises as $\mathrm{D} / \mathrm{G}$ ratios and the amorphous carbon content decreases (i.e., the electronic conductivity increases) [9]. The observation that some samples with low carbon contents outperform those with larger amounts of poorquality carbon is significant, and suggests that the amount of coating necessary to ensure good high-rate performance can be minimized provided that the structure is optimized. A considerable challenge is the temperature limitation $\left(<750-800^{\circ} \mathrm{C}\right)$ imposed by $\mathrm{LiFePO}_{4}$ synthesis conditions. For example, the graphene content and electronic conductivity are low for carbons prepared from polymeric precursors at temperatures below about $700^{\circ} \mathrm{C}$ $[22,23]$ but increase dramatically above this temperature. However, the considerable variations found in the in situ carbon of $\mathrm{LiFePO}_{4}$ samples suggest that much can be done to manipulate the structure, even considering the temperature constraints.

It is a common practice to use polymeric or organic additives as carbon sources during synthesis of $\mathrm{LiFePO}_{4}$ (see, e.g., reference 24). The Raman spectra and C, H, and N 
elemental analyses of $\mathrm{LiFePO}_{4}$ powders processed with poly(acrylonitrile), perylenetetracarboxylicdianhydride or other well-known graphite precursors, show that these additives do not decompose sufficiently at the relatively low synthesis temperatures to form an ideal coating [11]. In some cases, the addition of the precursors actually resulted in electrode materials with electrochemical performance inferior to that of samples processed without additives. In contrast, pyromellitic acid (PA, I) decomposes readily, as evidenced by lower $\mathrm{H} / \mathrm{C}$ ratios in the resulting products when compared to those processed with the above-mentioned additives. The $\mathrm{D} / \mathrm{G}$ ratio of the carbon coating is also increased over that materials synthesized without PA, but processed the same way (Figure 2).

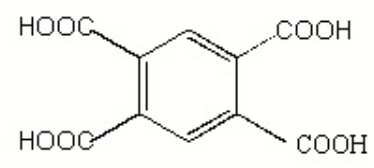

(I)

The overall carbon content in the final products generally increases somewhat as more PA is used, although this is very dependent upon the furnace conditions. $\mathrm{H} / \mathrm{C}$ ratios also rise, particularly above 8 wt. \%, indicating that complete decomposition becomes more difficult for large amounts of PA. Nevertheless, it is still possible to observe a broad reflection attributable to elemental carbon with some graphene character in the XRD pattern of $\mathrm{LiFePO}_{4}$ processed with 50 wt. \% PA (Figure 3).

The best rate behavior is obtained when $\mathrm{LiFePO}_{4}$ is processed with 4-8 wt. \% PA, which yields materials with in situ carbon content below 1 wt. \% [25]. For these 
electrodes, there is still not a good correlation between rate capability and carbon amount, suggesting that further improvement is possible.

It is well known that some iron compounds $[26,27,28]$ can catalyze the formation of graphite at relatively low temperatures. Graphite may precipitate upon decomposition of $\mathrm{Fe}_{3} \mathrm{C}$ (cementite) near $650^{\circ} \mathrm{C}$ during the production of cast iron, in a process known as "dusting". Furthermore, carbon nanotubes, which consist of curled graphene sheets, can be made at temperatures as low as $600-700^{\circ} \mathrm{C}$ using organic or polymeric carbon sources and iron compounds as promoters [29, 30]. An investigation into the mechanism of nanotube formation at $650^{\circ} \mathrm{C}$ using iron nitrate and acetylene [30] indicates that iron oxides form from the decomposition of iron nitrate, which then catalyze decomposition of the feeder gas to hydrogen and carbon. Iron oxide reacts with the carbon to form iron carbide, which then serves as nucleation sites for the nanotubes. Oxidation of $\mathrm{C}$ to $\mathrm{CO}$ or $\mathrm{CO}_{2}$, however, may compete with the nanotube formation.

These observations explain the variability in the in situ carbon structure found in $\mathrm{LiFePO}_{4}$ samples processed similarly, since iron oxides are common surface impurities. Anything more than trace oxidation of $\mathrm{LiFePO}_{4}$ samples during synthesis is clearly undesirable, severely limiting the options for producing graphitic carbon this way. Instead, addition of small amounts of graphitization catalysts such as iron nitrate, ferrocene, or ferrocene derivatives along with $\mathrm{PA}$ during $\mathrm{LiFePO}_{4}$ synthesis can be used to improve the carbon structure (Figure 2). When iron nitrate is added, there is no increase in the amount of in situ carbon but $\mathrm{H} / \mathrm{C}$ ratios are lowered and the rate behavior is improved to a limited degree. Addition of ferrocene results in both an overall increase 
in carbon content and a much lower $\mathrm{H} / \mathrm{C}$ ratio, and rate capability is improved dramatically (Figure 4).

Modeling work by Srinivasan et al. [31] shows that contact resistance between the porous electrode and the current collector is partly responsible for power limitations in $\mathrm{LiFePO}_{4}$ cells. Coating the current collector on the cathode side with a thin conductive carbon coating can decrease the contact resistance and results in much better high rate performance (Figure 5).

The behavior at high rates of the $\mathrm{LiFePO}_{4}$ used in the cells in Figure 5 compares favorably to those of $\mathrm{LiFePO}_{4}$ samples from several other sources [25] when cell design parameters are normalized 32]. However, further advances are still needed to achieve the high power required by HEV applications. The primary particle size of this material averages several hundred $\mathrm{nm}$, and the particle size distribution is very wide. Interestingly, the high power performance is equivalent to, or somewhat better than that of samples from other sources with significantly smaller average primary particle sizes and narrower particle size distributions. This suggests that more progress can be realized just by narrowing the particle size distribution. It may not be absolutely necessary to engineer extremely small primary particles, which might have an adverse impact on tap density and exacerbate reactivity with electrolytic solutions. A narrower particle size distribution most likely can be achieved by better mixing; the presence of some large particles in current materials [25] suggests that carbon or carbon precursors, which inhibit grain growth, are not evenly distributed throughout the samples. At present, the optimum amount of carbon that allows maximal power capability without overly compromising energy density is unknown, but is certain to depend on particle morphology. A recent 
transmission electron microscopy/energy filtered imaging study of $\mathrm{LiFePO}_{4}$ processed with ferrocene and PA shows that the carbon coating on primary particles is as thin as 2 nm [33]. It is not likely that carbon coats all the particles evenly in these samples, however. Better homogeneity of the carbon coating on $\mathrm{LiFePO}_{4}$ particles may also lead to increased power capability. Future work in this laboratory will be directed towards these issues.

\section{Conclusions}

The electrochemical performance of $\mathrm{LiFePO}_{4}$ is greatly enhanced when the structure of the in situ carbon covering the particles is improved. This may be achieved by adding small amounts of pyromellitic acid and graphitization catalysts such as iron nitrate or ferrocene during processing. The overall carbon content is still below 2 wt. \% but the graphene content is higher and the $\mathrm{H} / \mathrm{C}$ ratio is reduced compared to materials prepared without the additives. Further advances may be realized when the particle size distribution of samples is narrowed and the coating coverage is made more homogeneous.

\section{Acknowledgment}

This work was supported by the Assistant Secretary for Energy Efficiency and Renewable Energy, Office of FreedomCAR and Vehicle Technologies of the U.S. Department of Energy under contract no. DE-AC03-76SF00098. We would like to thank Dr. Gao Liu of Lawrence Berkeley National Laboratory for providing carbon-coated current collectors. 


\section{References}

1. S. Shi, L. Liu, C. Ouyang, D-S. Wang, Z. Wang, L. Chen, and X. Huan, Phys. Rev., 68 (2003) 195108-1-195108-5.

2. S.-Y. Chung, J. T. Bloking, and Y.-M. Chiang, Nat. Mater., 2 (2002) 123-128.

3. N. Ravet, A. Abouimrane, and M. Armand, Nat. Mater., 2 (2003) 702-703.

4. P. S. Herle, B. Ellis, N. Coombs, and L.F. Nazar, Nat. Mater., 3 (2004) 147-152.

5. N. Ravet, J. B. Goodenough, S. Besner, M. Gauthier, and M. Armand, Abstract 127, The Electrochemical Society and The Electrochemical Society of Japan Meeting Abstracts, Vol 99-2, Honolulu, HI, Oct 17-22, 1999.

6. H. Huang, S.-C. Yin, and L.F. Nazar, Electrochem. and Sol. State Lett., 4 (2001) A170-A172.

7. Z. Chen and J. R. Dahn, J. Electrochem. Soc., 149 (2002) A1184-A1189.

8. R. Kostecki, B. Schnyder, D. Alliata, X. Song, K. Kinoshita, and R. Kötz, Thin Solid Films, 396 (2001) 36-43.

9. M. M. Doeff, Y. Hu, F. McLarnon, and R. Kostecki, Electrochem. and Sol. State Lett. 6 (2003) A207-A209.

10. K. Kinoshita, Carbon: Electrochemical and Physicochemical Properties, Wiley Interscience, New York 1988.

11. Y. Hu, M. M. Doeff, R. Kostecki, and R. Fiñones, J. Electrochem. Soc., 151 (2004) A1279-1285.

12. S. Yang, P. Y. Zavalij, and M. S. Whittingham, Electrochem. Commun., 3 (2001) 505-508. 
13. S. Franger, F. Le Cras, C. Bourbon, and H. Rouault, J. Power Sources, 119-121 (2003) 252-257.

14. J. Barker, M.Y. Saidi, and J. L. Swoyer, J. Electrochem. Soc. , 150 (2003) A684A688.

15. R. Dominko, J. M. Goupil, M. Bele, M. Gaberscek, M. Remskar, D. Hanzel, and J. Jamnik, J. Electrochem. Soc., 152 (2005) A858-A863.

16. A. Audemer, C. Wurm, M. Morcrette, S. Gwizdala, and C. Masquelier, World Patent WO 2004/001881 (2003).

17. F. Croce, A. D’Epifanio, J. Hassoun, A. Deptula, T. Olczac, and B. Scrosati, Electrochem. and Sol. State Lett., 5 (2002) A47-A50.

18. G. Arnold, J. Garche, R. Hemmer, S. Ströbele, C. Vogler, and M. WohlfahrtMehrens, J. Power Sources, 119-121 (2003) 247-251.

19. M. Higuchi, K. Katayama, Y. Azuma, M. Yukawa, and M. Suhara, J. Power Sources, $119-121(2003)$ 258-261.

20. M. Herstedt, M. Stjerndahl, A. Nyten, T. Gustafsson, H. Rensmo, H. Siegbahn, N. Ravet, M. Armand, J. O. Thomas, and K. Edstrom, Electrochem. and Sol. State Lett., 6 (2003) A202-A206.

21. A. Yamada, S. C. Chung, and K. Hinokuma, J. Electrochem. Soc., 148 (2001) A224A229.

22. D. Alliata, R. Kostecki, X. Song, K. Kinoshita, and R. Kötz, Abstract 68, The $10^{\text {th }}$ International Meeting on Lithium Batteries, Como, Italy, May 28-June 2, 2000.

23. Z. Sun, X. Shi, X. Wang, and Y. Sun, Diamond Relat. Mater., 8 (1999) 1107-1113. 
24. H. Huang, S.-C. Yin, and L.F. Nazar, Electrochem. and Sol. State Lett., 4 (2001) A170-A172.

25. J. D. Wilcox, M. M. Doeff, and R. Kostecki, manuscript in preparation.

26. S. R. Dhakate, R. B. Mathur, and O.P. Bahl, Carbon, 35 (1997) 1753-1756.

27. Y. A. Kim, T. Matusita, T. Hayashi, M. Endo, M. S. Dresselhaus, Carbon, 39 (2001) 1747-1752.

28. Y.-G. Wang, Y. Korai I. Mochida, K. Nagayama, H. Hatano, N. Fukuda, Carbon, 39 (2001) 1627-1634.

29. C. Emmenegger, J.-M. Bonard, P. Mauron, P. Sudan, A. Lepora, B. Grobety, A. Züttel, and L. Schalpbach, Carbon, 41 (2003) 539-547.

30. N. I. Maksimova, O. P. Krivoruchko, G. Mestl, V. I. Zaikovskii, A. L. Chuvilin, A.

N. Salanov, and E.B. Burgina, J. Mol. Cat. A, 158 (2000) 301-307.

31. V. Srinivasan and J. Newman, J. Electrochem. Soc., 151 (2004) A1517-A1529.

32. K. Striebel, J. Shim, V. Srinivasan and J. Newman, J. Electrochem. Soc., 152 (2005) A664-A670.

33. H. Gabrisch, J. D. Wilcox, and M. M. Doeff, manuscript in preparation. 


\section{Figure Captions}

Figure 1. Photographs of $\mathrm{LiFePO}_{4}$ powders containing varying amounts of in situ carbon. The first three samples were prepared by sol-gel synthesis following procedures outlined in reference 11 , and the rightmost sample was prepared by the solid-state reaction described by Yamada et al. [20].

Figure 2. Raman spectra of $\mathrm{LiFePO}_{4}$ samples processed with and without additives as indicated. The D and $\mathrm{G}$ bands of in situ carbon are marked. The band at $942 \mathrm{~cm}^{-1}$ corresponds to the symmetric vibration of the $\mathrm{PO}_{4}$ group in $\mathrm{LiFePO}_{4}$.

Figure 3. XRD pattern of a $\mathrm{LiFePO}_{4}$ sample processed with 50 wt. \% PA. The 002 reflection of elemental carbon with some graphene character is marked in the inset.

Figure 4. Rate capabilities of electrodes containing $\mathrm{LiFePO}_{4}$ samples processed with and without additives as indicated, in lithium cells at room temperature. In situ carbon contents are $0.7 \%$ for the sample processed without additives, $0.76 \%$ for the sample processed with $6 \% \mathrm{PA}$, and $1.45 \%$ for that processed with $6 \% \mathrm{PA}$ and $1 \%$ ferrocene.

Figure 5. Rate capabilities of electrodes containing $\mathrm{LiFePO}_{4}$ processed with $6 \% \mathrm{PA}$ and $1 \%$ ferrocene $(1.45 \% \mathrm{C})$, with and without carbon-coated current collectors in lithium cells at room temperature. 


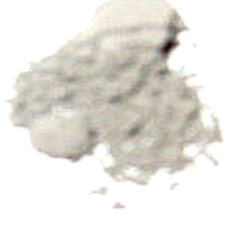

$0.3 \% \mathrm{C}$

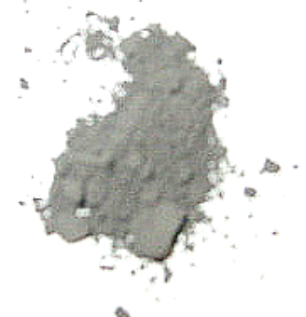

$0.7 \% \mathrm{C}$

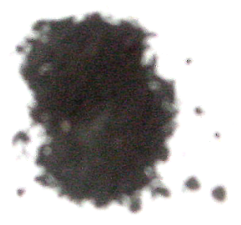

$1.15 \% \mathrm{C}$

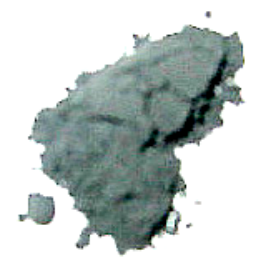

$1.5 \% \mathrm{C}$

Figure 1 


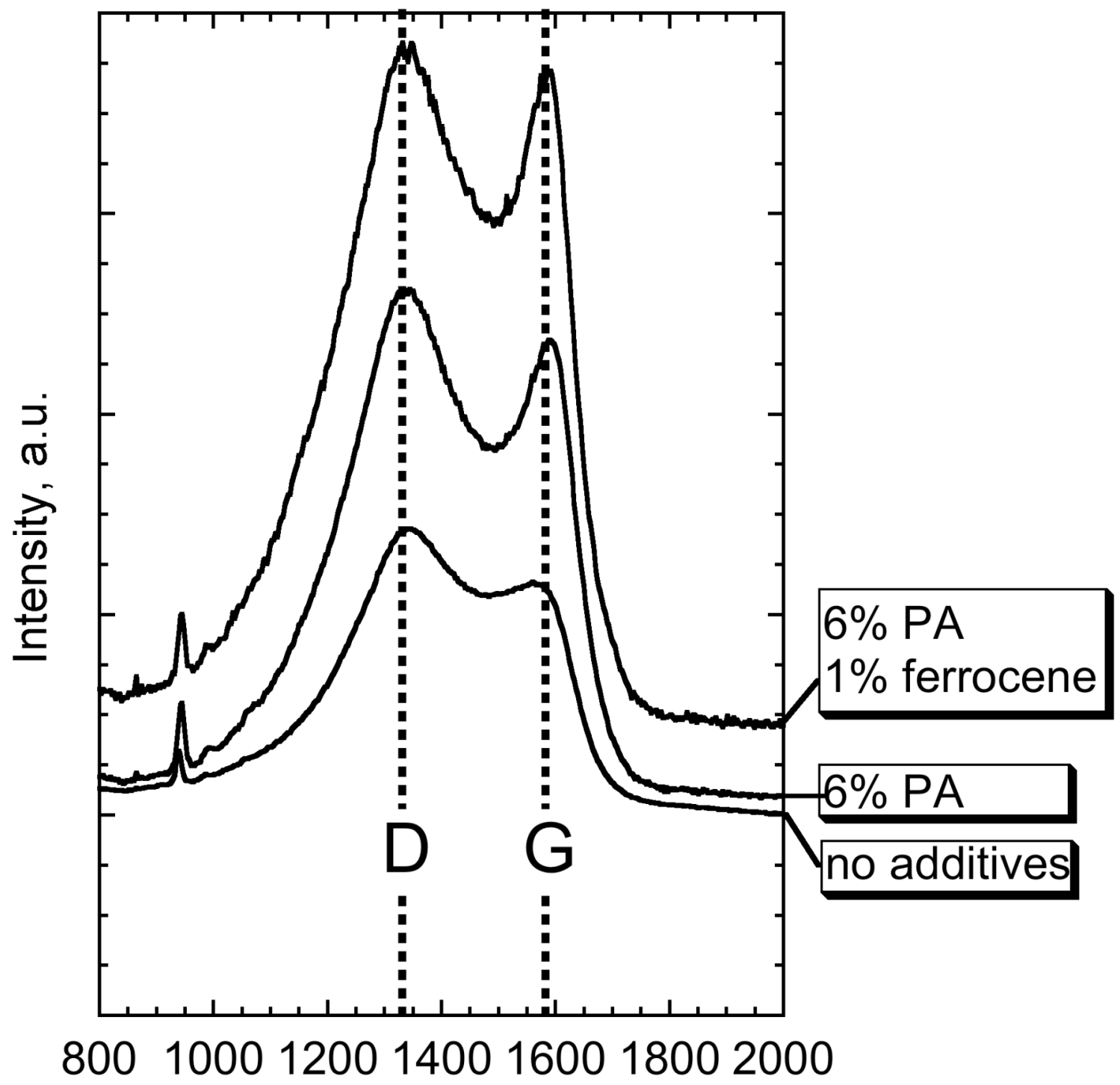

Raman shift, $\mathrm{cm}^{-1}$

Figure 2 


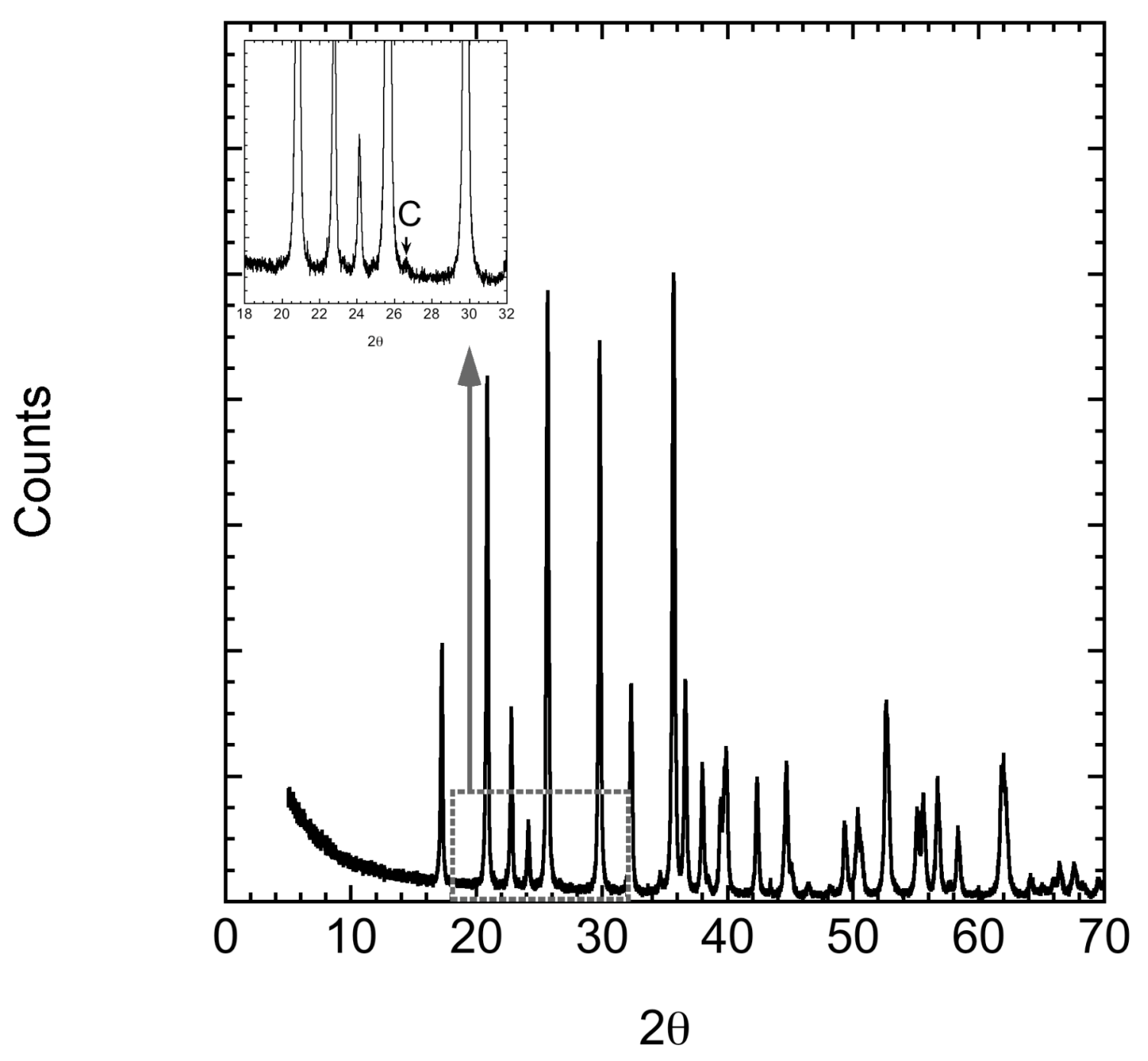

Figure 3 


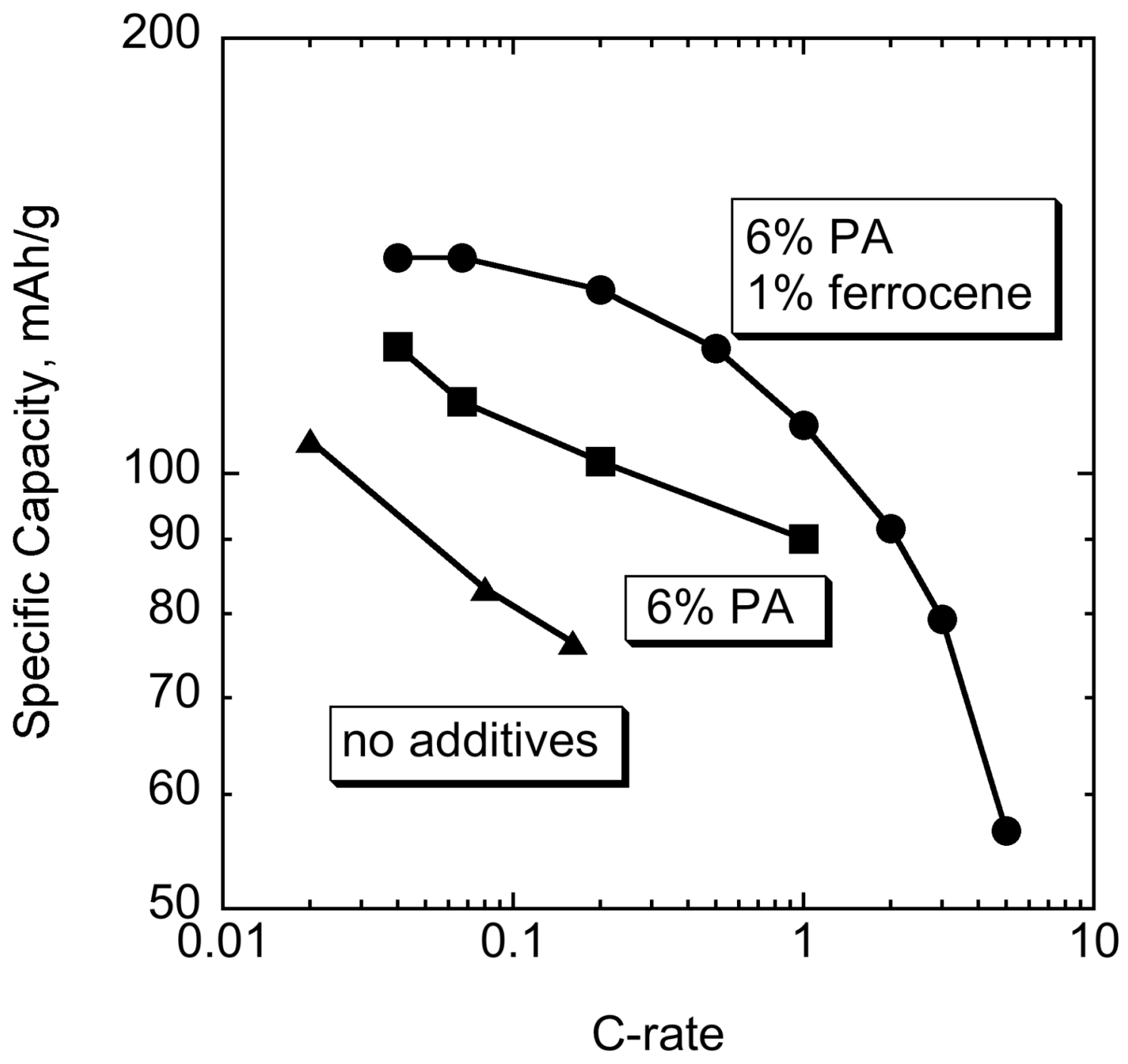

Figure 4. 


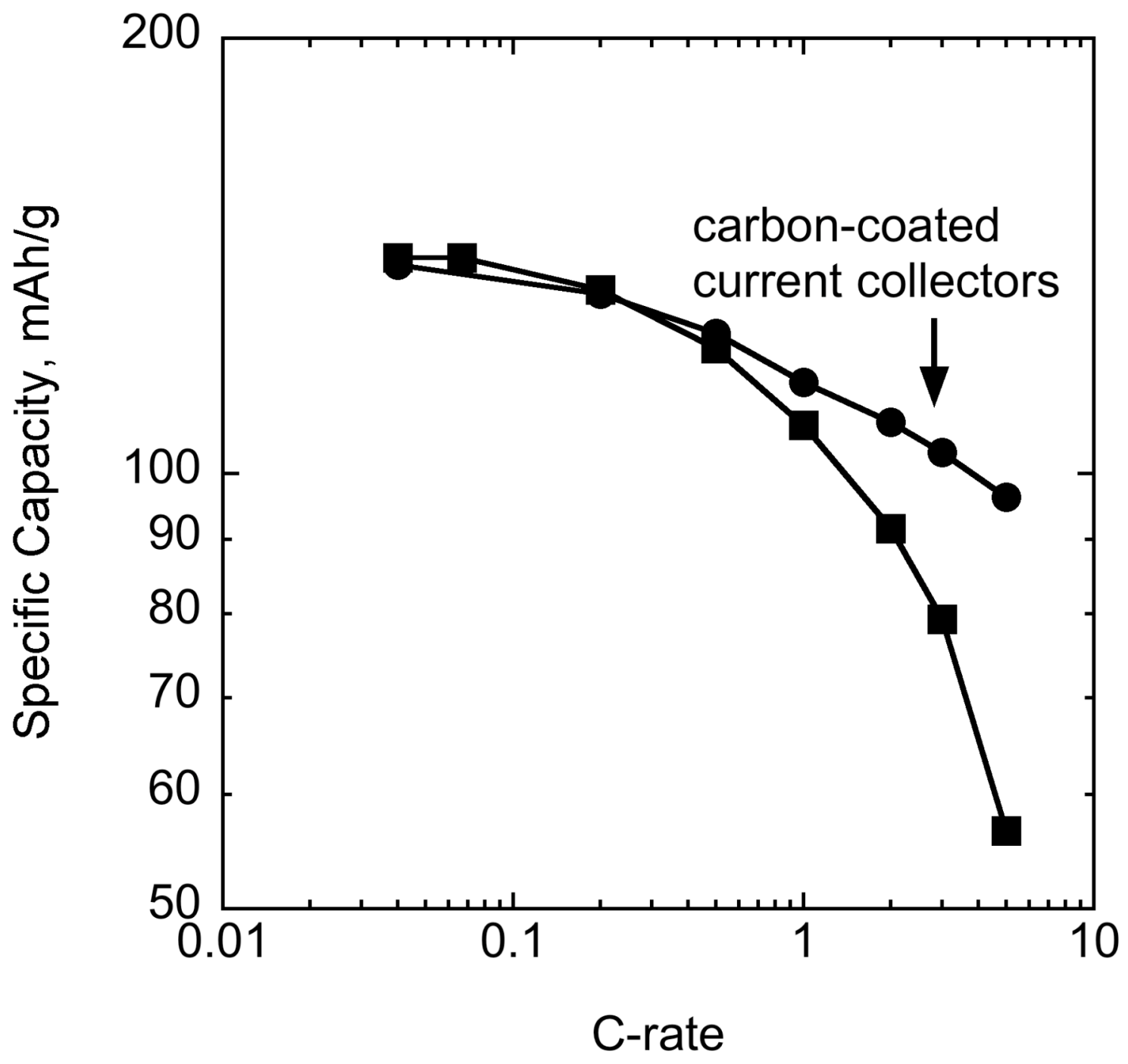

Figure 5 